\section{A behavioral and serological survey on HIV prevalence among prisoners in Benin}

S. Hessou, ${ }^{1}$ V. Dougnon, ${ }^{2}$

Y. Glele-Ahanhanzo, ${ }^{3}$ B.C.A. Imorou, ${ }^{4}$

C. Ahoussinou, ${ }^{5}$ B. Legba, 2,6

D.M. Zannou, ${ }^{1}$ L. Baba-Moussa ${ }^{6}$

${ }^{1}$ National Reference Center for the Research and Management of AIDS;

${ }^{2}$ Research Unit, Microbiology and Pharmacology of Natural Substances, Research Laboratory in Applied

Biology, Polytechnic School of Abomey-

Calavi, University of Abomey-Calavi;

${ }^{3}$ Regional Institute of Public Health,

University of Abomey-Calavi; ${ }^{4}$ National

Program for the Fight Against AIDS in

Benin, Ministry of Health;

${ }^{5}$ Independant Consultant; ${ }^{6}$ Laboratory

of Biology and Molecular Typing in

Microbiology, University of Abomey-

Calavi, Benin

\section{Abstract}

Cases of HIV are common in Benin, with infection rates varying according to socioeconomic and cultural factors, and by region. Certain segments of the population, such as prison inmates, sex worker clients and truck drivers are at high risk for HIV/AIDS. The aim of this study is to identify which behavioral and serological indicators contribute to the spread of HIV among prisoners. A total of 496 inmates from prisons located in all major cities in Benin were surveyed. Data was collected through interview sessions carried out using a questionnaire and through blood samples. The results show that most inmates are Beninese (83.5\%), and the average age is 33 years (range: 14-80 years). No prisoner reported using a condom the last time they engaged in sexual intercourse. Blood exposure was found in $14.6 \%$ of inmates and HIV was detected in $1.4 \%$ of cases. Our analysis indicates that the length of detention and gender are factors that influence HIV status. However, age, education, nationality and HIV awareness had no significant effect on HIV prevalence among inmates. The results highlight the need to raise awareness in prisons about HIV. This can be achieved by strengthening communication strategies and by organizing HIV and sexually transmitted diseases information sessions for both prison officers and inmates.

\section{Introduction}

HIV/AIDS is currently the world's fourth deadliest disease. ${ }^{1}$ It is considered a public health issue and HIV is mostly transmitted through STDs. In 2014, UNAIDS estimated that 35 million people worldwide were living with HIV at the end of 2013. It is also estimated that, in 2013 , there were 2.1 million new infections, which represents a decrease compared to 2001 when 3.4 million new cases are believed to have occurred. There has also been a $35 \%$ drop in the HIV-related deaths, declining from 2.3 million in 2005 to 1.5 million in 2013. SubSaharan Africa has the highest number of HIV cases: estimates are that between 23.5 and 26.1 million people in the region are infected, which represents roughly 7 out of 10 cases worldwide. ${ }^{2,3}$

HIV cases are common in Benin although infection rates vary according to socio-economic and cultural factors, and by region. Between 2006 and 2012, the rate of HIV infection in the country remained stable at $1.2 \%$ although certain departments and age groups saw an increase in the number of cases. ${ }^{4}$

The spread of HIV within prison populations in Africa is both a public health problem and a human rights issue. However, despite a significant increase in the amount of resources allocated to fighting HIV, prisons in Sub-Saharan Africa have received little attention. ${ }^{5}$ Data from various countries indicates that HIV rates among prisoners are 6 to50 times higher than in the rest of the adult population. The prevalence of HIV among inmates was greater by a factor of 6 in the United States, 10 in France, 27 in Switzerland and 50 in Mauritius. ${ }^{6}$ Similar differences have also been documented in Africa. Based on results from voluntary screening tests and ELISA tests, the HIV infection rate among prisoners was higher in Senegal $(2.7 \%)$, Zambia (27\%) and Nigeria (9\%). ${ }^{7}$

Second generation surveillance uses a behavioral and serologic approach to create monitoring systems adapted to the epidemic situation within a given country. This allows for resources to be allocated towards groups that are more likely to become infected. ${ }^{4,8,9}$ In Benin, little is known about the awareness, attitudes and practices of inmates when it comes to HIV and STDs. Therefore, the aim of this study is to help develop better decision-making tools by determining which behavioral and serological factors influence the likelihood of HIV infection among prisoners.
Correspondence: Victorien T. Dougnon, Research Unit in Microbiology and Pharmacology of natural substances, Research Laboratory in Applied Biology, Polytechnic School of Abomey-Calavi, University of Abomey-Calavi, Benin.

Tel. +229.9773 .6446$

Key words: inmates; HIV; behavioral and serological indicators; prisons; condoms.

Acknowledgments: authors are grateful to the Programme Nationale de Lutte contre le Sida and the Global Fund to Fight AIDS, Tuberculosis and Malaria for providing research funding; the Ministry of Health (Benin) through their departmental health directorates for their collaboration and technical assistance; the National Council for Fighting against HIV/ AIDS in Benin for contributing to the study's success; and the prisons administrators and inmates for their collaboration.

Contributions: the authors contributed equally. Conflict of interest: the authors declare no potential conflict of interest.

Received for publication: 11 April 2017.

Accepted for publication: 10 June 2017

This work is licensed under a Creative Commons Attribution NonCommercial 4.0 License (CC BY-NC 4.0).

(C) Copyright S. Hessou et al., 2017

Licensee PAGEPress, Italy

Journal of Public Health in Africa 2017; 8:678 doi:10.4081/jphia.2017.678

\section{Materials and Methods}

The monitoring survey systematically covered all the main prisons located in Benin's urban centres. Our study uses statistical methods to analyse cross sectional data on behavioral and serological indicators. Information was collected from inmates regarding behavioral practices that increase the likelihood of HIV infection. The survey data was also used to estimate HIV rates among inmates and to test for correlations between sexual practices and HIV status.

\section{Materials}

A lengthy interview questionnaire was used to analyze the behavioral practices of inmates. To collect serological data on the prison population, we used clean and unused syringes, alcohol tampons, gloves, paper filters and sealable plastic bags. 


\section{Methodology}

Ethical considerations and administrative provisions

Before the study was implemented, the Ministry of Health through the CER-ISBA considered the ethical implications of the survey and provided input. The committee approved the research protocol in November, 2015. In addition, authorization was obtained from the ministries of all three levels of education, the Interior Ministry and civil society groups. Involvement in the study was voluntary and participants could opt out at any time. Participants were also asked to sign a written consent form. To protect the privacy of inmates, all those associated with the implementation of the study signed a confidentiality agreement with the Programme National de Lutte contre le Sida (PNLS). ${ }^{10}$

\section{Study population and sampling procedure}

The survey was carried out in Benin's 10 prison centres. We used a stratified sampling method, defining the prisons as the strata and inmates as the sample units. The number of inmates to be surveyed in each prison was proportional to the size of the prison's population. In addition, we selected woman participants based on the percentage of female inmates. For each prison, secondary units were selected by dividing the total number of individuals to be surveyed by the number of houses or quarters. After the inmates were informed about the survey, cell leaders and peer educators were instructed on how it would be implemented. Cell leaders presented to the research team those who agreed to participate in the study and participants were accepted until the desired sample size was reached. Given the limited number of female inmates, all of them were invited to participate in the survey.

\section{Behavioral data}

Data was collected using a questionnaire that was divided into different sections. The interviews allowed the research team to gather data on the following modules: information regarding the questionnaire and the interview; general information; sexual history (number and types of partners); paid sexual encounters; condom use; understanding of HIV/AIDS and STD transmission modes and prevention measures; knowledge, opinions and attitudes regarding HIV/AIDS and prevention; and HIV screening.

\section{Health data}

The inmates could decide whether they wanted to participate in both stages of the study (questionnaire and blood test), partic- ipate only in the questionnaire, or provide blood samples along with identification information. Blood samples were taken and sent to the PNLS by qualified health workers. Blood samples were obtained on site by trained health workers and the test results were given to those who wished to know their serological status.

\section{Statistical analysis}

The behavioral and serological data collected was entered into EPIDATA 3.1 and any inconsistencies or errors during data entry were analyzed and corrected. The database was then transferred to SPSS 21 and sorted by strata, target group and gender. If required, the data was also ranked according to prison size. We used both univariate and multivariate analysis to examine the information gathered from the survey on behavioral practices. Both the Pearson chisquare test and the Fisher test were applied, using a significance level of $5 \%$. We also carried out a logistic regression to account for how behavioral factors might influence the spread of HIV.

\section{Results and Discussion}

\section{Results}

The number of people who were expected to participate in the study was 500 .

Table 1. Distribution of surveyed inmates by prison.

\begin{tabular}{lccc} 
Prisons & Prisoners enrolled & $\%$ total sample & Prisoners expected to enrol \\
Abomey & 72 & 14.5 & 70 \\
Abomey-Calavi & 38 & 7.7 & 41 \\
\hline Akpro-Missereté & 53 & 10.7 & 51 \\
Cotonou & 136 & 27.4 & 136 \\
\hline Kandi & 23 & 4.6 & 22 \\
Lokossa & 33 & 6.7 & 33 \\
\hline Natitingou & 34 & 6.9 & 34 \\
Ouidah & 24 & 4.8 & 23 \\
\hline Parakou & 35 & 7.1 & 36 \\
Porto-Novo & 48 & 9.7 & 54 \\
\hline Total & 496 & 100 & 500
\end{tabular}

Table 2. Distribution of surveyed inmates based on age, gender, education level and profession.

\begin{tabular}{lcc} 
Characteristics & \multicolumn{2}{c}{ Surveyed inmates } \\
& No & \\
Age $(\mathrm{n}=496)$ & & \\
$15-19$ & 20 & 4.0 \\
$20-24$ & 68 & 13.7 \\
$25-29$ & 103 & 20.8 \\
$30-34$ & 116 & 23.4 \\
$35-39$ & 78 & 15.7 \\
$40-44$ & 43 & 8.7 \\
$45-49$ & 31 & 6.2 \\
50 and older & 37 & 7.5 \\
Gender (n=496) & & \\
Male & 414 & 83.5 \\
Female & 82 & 16.5 \\
\hline Education level (n=495) & 153 & 30.9 \\
None & 138 & 27.9 \\
Primary & 204 & 41.2 \\
Secondary and higher & & \\
Profession (n=496) & 168 & 33.9 \\
Merchant/farmer/fisherman & 54 & 10.9 \\
Public or private professional & 43 & 8.7 \\
Driver/truck driver/taxi driver & 7 & 1.4 \\
Military serviceman/police officer & 193 & 38.9 \\
Artisan/artist & 31 & 6.2 \\
Other & & \\
& &
\end{tabular}


In total, 496 inmates were involved, which represents a $99.2 \%$ enrolment rate. The prisons located in Cotonou (27.4\%) and Abomey (14.5\%) house a significant portion of the prison population (Table 1).

\section{Socio-demographic characteristics of inmates}

The breakdown of prisoners according to age, gender, education level and profession

The average age of inmates is 33 years (range: $14-80$ years) and the median age was 32 years. More than four out of five inmates $(82.3 \%)$ are less than 25 years old and more than half are between 20 and 35 years of age. Moreover, $30.9 \%$ of inmates never attended school and more than half had not finished their primary education at the time of the study. Inmates practiced a variety of professions, with artisans representing that largest group (38.9\%), followed by traders and farmers $(33.9 \%)$. Public and private professionals represented $10.9 \%$ of the sampled prison population. Table 2 shows the breakdown of inmates by age, gender, and education level. In total, $83.5 \%$ of the prisoners that were surveyed were male compared to $16.5 \%$ who were female. The sex ratio of males per female was 5 to 1 .

\section{The breakdown of surveyed inmates by religious affiliation, nationality, marital status and length of incarceration}

Two out of three inmates surveyed were Christian (67.1\%). Muslims represent almost a fifth of the prison population (19.4\%), followed by adherents of traditional religions $(8.5 \%)$. Most of the prisoners are Beninese nationals $(87.9 \%)$, although some participants were from Togo (4.4\%) or Nigeria $(4.1 \%)$. More than half of inmates were married $(54.3 \%)$, one out of four were single $(25.2 \%)$ and $14.5 \%$ were in a non-marital relationship with one or more partners. Inmates who were divorced represented $4.2 \%$ of those surveyed. The average length of detention was 33.5 months although the median length was 12 months. Roughly a third of inmates $(35.2 \%)$ had already spent 6 months in prison and more than half $(50.6 \%)$ had been incarcerated for a year. Moreover, $8.7 \%$ of participants had already been to prison at least once. Among them, almost a third $(32.6 \%)$ had been incarcerated for 6 months and a fifth $(20.9 \%)$ spent more than 6 months in detention (Table 3).

\section{Tobacco alcohol and drug consump- tion by prison inmates}

More than half of inmates surveyed (54.7\%) are non-smokers; another 22.8\% stopped smoking after their incarceration, while $22.6 \%$ continued to use tobacco in prison. On average, participants who smoked were 19.4 years old and consumed an average of 5.1 cigarettes per day. The prisons located in in the departments of Borgou, Alibori and Ouémé have the highest concentration of smokers: Parakou (45.7\%), Kandi (30.4\%), Akpro Missérété $(28.3 \%)$ and Porto-Novo (27.3\%). More than half $(56.2 \%)$ of participants also reported consuming alcohol. Consumption was highest among inmates in Porto-Novo (81.3\%), Akpro-Missérété (75.0\%), Ouidah $(60.9 \%)$ and Parakou $(60.0 \%)$. As well, the alcoholic beverages that are most often consumed are beer $(74.1 \%)$, liquor $(74.1 \%)$ and wine $(39.1 \%)$. More than two thirds of prisoners $(68.5 \%)$ consume alcohol occasionally, and $6.7 \%$ report drinking two to three times per day. In addition, $9.7 \%$ of surveyed participants (48 out of 496) report having previously taken drugs. Among them, $45.8 \%$ (22) continued the habit in prison and $6.3 \%(n=3)$ reported using injectable drugs. Cannabis was the most widely used drug $(58.6 \%)$ followed by cocaine $(31.0 \%)$. Drugs are consumed both within the prison $(4.4 \%)$ as well as outside $(51.4 \%)$.

\section{Inmate sexual activities}

Sexual behaviour and condom use

In total, $10.3 \%(\mathrm{n}=495)$ participants reported having engaged in sexual intercourse during the prior month, of whom
$21.6 \%$ used a condom. In the case of male inmates, $14.3 \%(n=42)$ had sexual intercourse during the previous 12 months and only a third $(33.3 \%)$ used a condom. As well, five out of nine inmates $(55.6 \%)$ had engaged in anal penetration, including four out of six men $(66.7 \%)$ and one in three women $(33.3 \%)$.

\section{Sexual relationships in prison}

Prior to their incarceration, $51.2 \%$ of participants $(n=473)$ reported having more than one partner; most of those with multiple partners were men (96.3\%). We note that in prison no inmate had sexual intercourse with a fellow inmate.

\section{Awareness and attitudes towards HIV/AIDS among inmates Awareness among prisoners about the modes of HIV/AIDS transmission}

The main modes of HIV transmission mentioned by participants were unprotected anal or vaginal penetration $(67.1 \%)$ and injuries from contaminated objects $(63.5 \%)$. However, inmates also provided incorrect answers: out of those surveyed, $19.4 \%$ said that mosquito bites could lead to HIV infection and $14.7 \%$ said that the virus was the result of divine will (Figure 1)

\section{Health information in prison}

During their incarceration, inmates

Table 3. Distribution of surveyed prisoners by religious affiliation, nationality, marital status and length of incarceration.

\begin{tabular}{lcc} 
Variables & Surveyed inmates \\
& No & \\
Religion (n=496) & & \\
No religion & 19 & 3.8 \\
Traditional & 42 & 8.5 \\
Christian & 333 & 67.1 \\
Muslim & 96 & 19.4 \\
Other & 6 & 1.2 \\
Country of citizenship (n=496) & \\
Benin & 436 & 87.9 \\
Ghana & 7 & 1.4 \\
Togo & 22 & 4.4 \\
Niger & 20 & 4.1 \\
$\quad$ Other & 11 & 2.2 \\
\hline Marital status (n=496) & \\
Unmarried (no partner) & 125 & 25.2 \\
Unmarried (one or multiple partners) & 72 & 14.5 \\
Married (monogamous/polygamous relationship) & 269 & 54.3 \\
Divorced/Widow & 21 & 4.2 \\
Other & 9 & 1.8 \\
Length of incarceration (n=395) & & \\
0-6 months & 139 & 35.2 \\
7-12 months & 61 & 15.4 \\
13-24 months & 63 & 15.9 \\
25-36 months & 33 & 8.4 \\
37 months and more & 99 & 25.1 \\
\hline
\end{tabular}


could access health material on a variety of topics. In total, $65.5 \%$ of surveyed prisoners were given information about HIV/AIDS and more than half $(50.6 \%)$ received information regarding condoms (Figure 2).

\section{Incorrect views about HIV/AIDS}

There are still misunderstandings among inmates regarding HIV/AIDs. The notion that HIV can spread through mosquito bites was the most widely spread misconception $(35.9 \%)$, followed by the belief that people can become infected by sharing food with someone who has the virus $(20.6 \%)$ (Table 4).

\section{Access to care, prevention and screening for inmates}

Accessing care and prevention methods

Almost three four of four participants (74.2\%) said they know about an HIV screening clinic and $59.5 \%$ are aware that a treatment option exists. However, more than half of those surveyed (53.6\%) do not know the serological status of their partner (Table 5).

\section{HIV screening prior to survey}

Three out of four inmates $(72.8 \%)$ had already undergone a screening test and 93.6\% had received their results. Among this group, thirteen individuals had tested seropositive for HIV. These inmates came from all the prisons visited except for Abomey, Abomey-Calavi and Lokoss. Out of the thirteen prisoners, four of them (incarcerated in Kandi, Parakou, Ouidah and Natitingou) were using ARV drugs. Those incarcerated in Natitingou and Kandi reported receiving their ARV treatment in prison.

\section{Willingness to undergo HIV screening}

Table 6 shows the number of inmates in each prison who agreed to undergo a screening test. Among those who enrolled in the study, $97.6 \%$ agreed to be screened.

\section{HIV prevalence among prisoners}

Among the 494 inmates who agreed to be screened, 7 tested positive. Consequently, we estimate that the rate of HIV infection among the prison population in Benin is $1.4 \%$ with a $95 \%$ confidence interval between 0.4 and 2.4 .

\section{Association between HIV prevalence and socio-demographic characteristics}

Our analysis did not establish any link between HIV status and age. Specifically, there was no significant difference in terms of HIV prevalence between inmates who were 29 years of age or younger and those who were older.

\section{Factors associated with HIV prevalence among inmates}

The factors associated with HIV prevalence are presented in Table 7. The level of educational, religious affiliation, nationality, marital status and knowledge of at least one HIV transmission mode had no effect on HIV status. However, HIV rates were higher among male inmates and those serving a sentence of more than one year $(\mathrm{P}<0.05)$.

\section{Discussion}

The aim of this study was to determine the severity of behavioral and serological indicators of HIV/AIDS among prisoners. The prevalence of HIV among surveyed inmates was $1.4 \%(7 / 494)$, which is higher than the rate among the general population in Benin $(1.2 \%){ }^{4}$ It is also higher than the rate estimated by previous studies for other social groups at risk in Benin such as truck drivers $(1.2 \%)$ and sex workers $(1.3 \%)$.

However, studies of prison populations in other African countries have reported higher rates of HIV infection in Mauritania (3.9\%), Nigeria (9\%), Burkina-Faso (11\%), Zambia (27\%), the Ivory Coast (28\%) and South Africa (41.4\%). 5,11 These infection rates among inmates are directly related to the level of HIV prevalence in each country.

The rate of HIV infection within the prison population in Benin is dependant on behavioral indicators such as drug consumption, condom use and HIV/AIDS awareness. Only $21.6 \%$ of the prisoners surveyed who had sexual intercourse during the previous month had used a condom.

Table 4. Misconceptions about HIV/AIDS.

\begin{tabular}{lccc} 
Questions & Respondent's answer & Respondents & 95\% CI \\
Can a person get HIV through mosquito bites? & Yes & 196 & 35.9 \\
Can a person get HIV by sharing food with an infected individual? & Yes & 102 & 20.6 \\
\hline Can a person who appears healthy in fact be infected with HIV? & No & $19.8-21.4$ \\
\hline
\end{tabular}

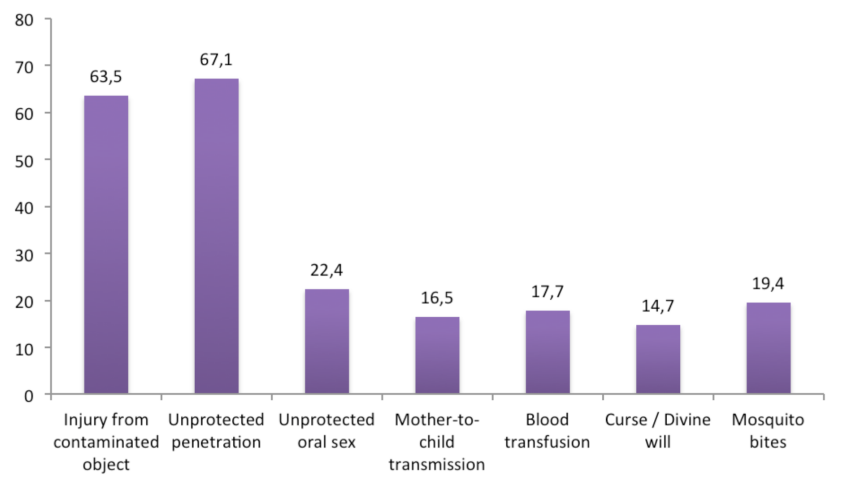

Figure 1. Awareness about the modes of HIV/AIDS transmission.

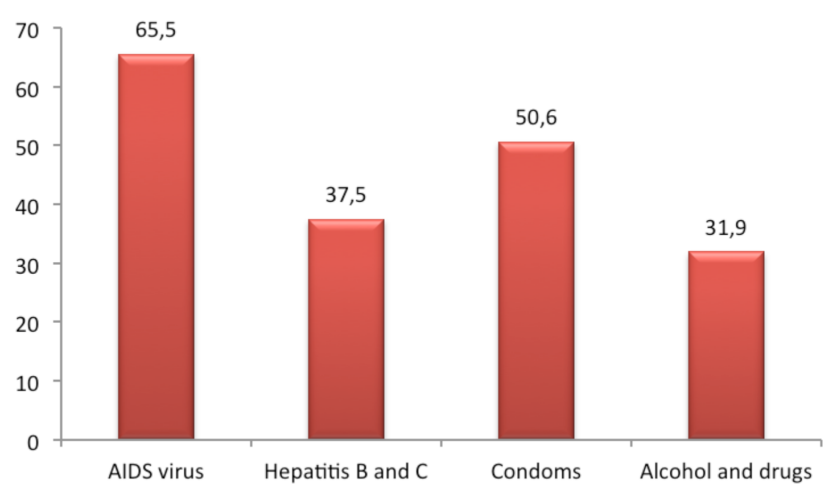

Figure 2. Access to health information in prison regarding HIV/AIDS and sexually transmitted diseases. 
More than half of participants had multiple partners prior to incarceration. In addition, most inmates are aware that unprotected vaginal or anal sex $(67.1 \%)$ or injury from contaminated objects $(63.5 \%)$ increases the risk of getting HIV. This logical association between HIV/AIDS prevalence and certain behavioral indicators has been found in other studies. For example, in Mauritania, HIV rates were higher among prisoners in Nouakchott, of whom only $7.4 \%$ had perfect knowledge about the modes of HIV/AIDS transmission. ${ }^{12}$ In total, $7 \%$ of inmates had reported using drugs. In our study, we did not establish any link between drug consumption and HIV/AIDS preva- lence. However, excessive drug use can lead to high-risk behaviors that facilitate the spread of STDs and HIV (not using a condom, non-consensual sex, sexual violence, casual sexual intercourse). For instance, previous studies conducted in Senegal and the Seychelles have shown that drug dealers have a higher incidence of HIV/AIDS. ${ }^{13,14}$ Thi Thu Vu et al. ${ }^{15}$ also showed a significant correlation between methamphetamine use and HIV infection. In our study, a limited number of participants $(6.3 \%)$ reported having injected drugs. While the percentage may be relatively low, the use of such drugs is a cause for concern given that up to $10 \%$ of HIV cases worldwide are attributable to

Table 5. Access to care and prevention methods for inmates.

$\begin{array}{lcc}\text { Characteristics }(\mathrm{n}=\mathbf{4 9 6}) & \text { No } & \% \\ & & \\ \text { Inmate knows of an HIV screening clinic } & 368 & 74.2 \\ \quad \text { Yes } & 128 & 25.8 \\ \quad \text { No } & & \\ \text { Inmate knows about HIV treatments } & 295 & 59.5 \\ \quad \text { Yes } & 201 & 40.5 \\ \quad \text { No } & & \\ \text { Inmate knows partner's serological status (married) } & 230 & 46.4 \\ \quad \text { Yes } & 266 & 53.6 \\ \quad \text { No } & \end{array}$

Table 6. Number of inmates wiling to undergo HIV screening.

\begin{tabular}{|c|c|c|c|}
\hline \multirow[t]{2}{*}{ Prison site } & \multicolumn{2}{|c|}{ Screening conducted } & \multirow[t]{2}{*}{ Number } \\
\hline & Yes & No & \\
\hline Abomey & 100.0 & 0 & 72 \\
\hline Abomey-Calavi & 100.0 & 0 & 38 \\
\hline Akpro-Missérété & 100.0 & 0 & 53 \\
\hline Cotonou & 100.0 & 0 & 136 \\
\hline Kandi & 100.0 & 0 & 23 \\
\hline Lokossa & 100.0 & 0 & 33 \\
\hline Natitingou & 97.0 & 2.9 & 34 \\
\hline Ouidah & 100.0 & 0 & 24 \\
\hline Parakou & 97.1 & 2.9 & 35 \\
\hline Porto-Novo & 100.0 & 0 & 48 \\
\hline Total & 99.6 & 0.4 & 496 \\
\hline
\end{tabular}

Table 7. Analysis of factors associated with HIV prevalence among inmates.

\begin{tabular}{lccc} 
Variables & \multicolumn{2}{c}{ HIV infection } & P-value \\
& Positive & Negative & \\
Under 29 years of age & 34.6 & 28.6 & 0.74 \\
30 years of age and older & 38.9 & 57.1 & 0.32 \\
\hline Gender = male & 83.5 & 42.9 & 0.00 \\
Primary or secondary school attendance & 30.7 & 42.9 & 0.49 \\
\hline Religious affiliation = Christian & 67.6 & 57.1 & 0.55 \\
Nationality = Benin & 88.7 & 71.4 & 0.15 \\
\hline Inmate knows at least one HIV transmission mode & 84.9 & 71.4 & 0.32 \\
Marital status = married & 54.1 & 71.4 & 0.36 \\
\hline Prison sentence is greater than 1 year & 51.3 & 14.3 & 3, \\
\hline
\end{tabular}

\section{References}

1. UNAIDS. Rapport d'activité 2015 sur la riposte au sida dans le monde. 2015. Available from: http://www.unaids.org/sites/default/file s/media_asset/JC2702_GARPR2015gu idelines_fr.pdf

2. Family Health International. Evaluating programs for HIV/AIDS prevention and 
care in developing countries: a handbook for program managers and decision makers. 2001. Available from: http://www.saathii.org/ovc/guidelines_an d_tools/M\&E\%20FHI\%20guide.pdf

3. Ministere de la Santé, de la Solidarite et de la Promotion du Genre, Direction Nationale de la Santé, Direction de Lutte contre le Sida. Guide national pour la surveillance de deuxième génération du VIH/SIDA. Union des Comores, 2011. Available from: http://publiciterre.org/GuideNationalSu rveillance 2 eGeneration $\% 20 \mathrm{VIH}$ Comores2011.pdf

4. Institut National de la Statistique et de l'Analyse Économique, Ministère du Développement, de l'Analyse Économique et de la Prospective, Gouvernement du Bénin. Enquête démographiques de santé 2011-2012. Available from: http://microdata.worldbank.org/index.php/catalog/1953/export

5. Office des Nations Unies contre la drogue et le crime. Le VIH en prison: possibilité d'intervention en Afrique Subsaharienne. 2007. Available from : https://www.unodc.org/documents/hivaids/publications/UNODC_UNAIDS WB_2007_HIV_and_Prisons_in_Afric a-FR.pdf

6. Macher A, Goosby A. The incarcerated: a report from the 12th world AIDS conference. 1998. Available form: http://www.hopkins-aids.edu/geneva/ hilites_macer.html
7. Stubblefield E. Prisons and jails worldwide - Update from the 13th international Conference on AIDS' HEPP News 2000.

8. Family Health International. Enquêtes de surveillance comportementale: guide pour enquêtes répétées de surveillance comportementale au sein de populations exposées au VIH. 2002. Available from: http://pdf.usaid.gov/pdf_docs/Pnacr618 .pdf

9. PNLS. Enquête de surveiillance de deuxiieme generatiion des IIST/VIIH/SIIDA au Beniin (ESDG 2008). Available from: https:/www.afdb.org/fileadmin/upload s/afdb/Documents/Evaluation-Reports$\mathrm{S} h$ a $\mathrm{r}$ e d - W i t h OPEV_/Benin_VIH_SIDA_Fr_.pdf

10. PNLS, IST. Enquête comportementale et de séroprévalence du VIH chez les utilisateurs de droguesau Togo en 2011. Available from: http://www.pnls.tg/rapports/Rapport1.pdf

11. Jürgens R, Nowak M, Day M. HIV and incarceration: prisons and detention. $\mathrm{J}$ Int AIDS Soc 2011;14:26.

12. Ba K, Keita M, Fall-Malick FZ, et al. Serological and behavioral survey on HIV/AIDS among prisoners in Nouakchott (Mauritania). Bull Soc Pathol Exot 2015;08:208-12.

13. Bibi J, Faure J, Johnston LG, 2011. Enquête de séroprévalence et études comportementales chez consommateurs de drogues injectables, 2011,
Seychelles.

14. Agence Nationale de Recherche sur le Sida et les hépatites virales. Résultats de l'enquête de prévalence et comportementale chez les usagers de drogues injectables de la région de Dakar (ANRS 12243/CNLS/IMEA/FM). In: Rapport scientifique ANRS - Sénégal 2011/2012. Available from: http://mediatheque.lecrips.net/doc_num .php?explnum_id=37695

15. Vu NTT, Maher L, Zablotska I. Amphetamine-type stimulants and HIV infection among men who have sex with men: implications on HIV research and prevention from a systematic review and meta-analysis. J Int AIDS Soc 2015;18:19273.

16. Smith AD, Tapsoba P, Peshu N, et al. Men who have sex with men and HIV/AIDS in sub-Saharan Africa. Lancet 2009;374:416-22.

17. Kyomya M, Todyrs KW, Amon JJ. Laws against sodomy and the HIV epidemic in African prisons. Lancet 2012:380:310-2.

18. Beyrer C, Baral SD, Griensven F, et al. Global epidemiology of HIV infection in men who have sex with men. Lancet 2012;380:367-7.

19. Senok AC, Botta GA. Human immunodeficiency virus and hepatitis virus infection in correctional institutions in Africa: is this the neglected source of an epidemic? J Med Microbiol 2006;55: 481-2. 